\title{
The Importance of Health Education and Environmental Hygiene Practices in Overcoming Children Diarrhea: What Does Healthcare Professionals Need to Know?
}

\author{
Chairun Nasirin \\ College of Health Sciences \\ STIKES Mataram \\ Mataram, Indonesia \\ chairun.nasirin@stikes-mataram.ac.id
}

\begin{abstract}
Health services are essential in improving the quality of children's health during the growth period, where the child always interacts with the environment so that there is exposure to either virus or bacterial diseases that can cause diarrhea. Meanwhile, health problems in the child are indeed not separate from the lack of food and not the cleanliness of the environmental hygiene of children's residence. The purpose of this study is to explain the importance of the role of professional health officers in addressing the health of children suffering from diarrhea due to food contamination and lack of parental supervision in providing adequate nutritional intake in children during the period of growth. The research methodology used a quantitative method with non-probability sampling techniques; the goal is to find out the role of the professional health workforce in addressing the problem of diarrhea hazards occurring in children. The Result of the study shows that $42.7 \%$ of respondents with diarrhea are accompanied by dehydration; this is due to the parents' cannot control the cleanliness of food and nutrition. Hence, the occurrence of diarrhea in children due to the gross environmental sanitation factor. By the finding of this study, to reduce the prevalence of diarrhea in children who are found in rural areas, parents' participation and professional health care professionals are needed by all communities in addressing the problems of stomach disorders in children causing diarrhea to inhibit the growth of children's health.
\end{abstract}

Keywords-public health, healthcare, diarrhea, nurses, children

\section{INTRODUCTION}

Every country indeed expects health development aimed at improving the healthy living ability for everyone to achieving public health expectations highest as a manifestation of welfare for all citizens. By providing quality healthcare services to all elements of society can undoubtedly improve quality human resources. Therefore it is necessary for the role of healthcare professionals who can handle national health problems and, as a form of health care personnel, respond to the state according to the Ethics of health workers. The intended role of healthcare personnel includes the purpose of implementing health for all communities. This is following the mandate from health organizations that always expect health both physically and mentally and socially so that all elements of society are free from disease.
Child health problems are one of the main issues in the health field that is currently occurring in Indonesia. Based on these reasons, child health problems are prioritized in the planning or structuring of the nation's development, so the success of health development can measure from declining levels of illness and increasing life expectancy. Therefore, the child's health becomes extremely important to the parents who have children to know the various health problems of the child, including children's illness, prevention, and treatment. On the other hand, the health of a child should be observed during the growth period; this is due to the child began to interact with the surrounding environment children grew up increasing the risk of exposure to some diseases either from viruses or bacteria that could cause diarrhea.

The diarrhea disease that occurs by a sufferer is generally characterized by increasing the frequency of defecation more than three times daily and accompanied by changes in the consistency of stool impurities transformed into a liquid. Symptoms of the disease are followed by vomiting due to impaired acid and electrolyte balance. But if the diarrhea sufferer has much loss of fluid and electrolytes, the following symptoms are the occurrence of dehydration so that it starts to see weight loss, mucous membranes of the lips and mouth, and skin appear dry. Diarrhea is not a disease that comes by itself; usually, there is a trigger to diarrhea, that is, the occurrence of infections caused by bacteria, viruses, and parasites, allergic to food or certain medications.

Diarrhea occurs due to the increased frequency of excessive bowel movements causing the loss of water content in the human body. The diarrheal disease can be a severe problem when the fluid that is excreted by the body is excessive but not balanced with adequate nutritional intake required by patients with diarrhea when dehydrated. The causes of diarrhea are infections, allergies, bacteria or viruses, parasites, and artificial sweeteners. The occurrence of diarrhea in children is generally influenced by the presence of contaminated bacteria in unhygienic foods, causing the sufferer to frequent bowel movements. And the consequences, the sufferer is much fluid deficiency in his body. The need body needs much fluid intake because our part of the body mostly consists of water particles. Therefore, all the process of parsing food occurring in the body requires much water. The loss of fluid in the body can cause by the amount of fluid incurred along with the stool so 
that when a person lacks water in his body, then the shape of the person can cause the shock of the body; therefore, it can become hazardous for human survival. According to [1] the lack of fluid in the body can be caused by the amount of fluid that comes out with the stool or the loss of liquid contained in the human body when eating much food and very little drink water after consuming the meal.

The occurrence of diarrhea besides caused by hygienic factors is undoubtedly caused by excessive stimulation of defecation so that the consistency of stool becomes liquid that is accompanied by the continuous discharge of mucus. The stimulation of defecation is the cause of excessive pain in the sufferers of diarrhea, resulting in continuous bowel movements so that the water content in the body of the sufferer is increasingly reduced, causing the sufferer to feel weak [2]. The lack of defecation in patients with diarrhea with the frequency of many fluids discharged with stool can undoubtedly lead to a sudden loss of electrolyte fluid in the body [3]. Therefore, the cause of diarrhea is also certainly not apart from the occurrence of infection due to viral or germ pathogens and psychological factors as well as food factors consumed by diarrhea sufferers.

The signs and symptoms of diarrhea in diarrhea sufferers can be known when the person is excessive bowel movements accompanied by prolonged heartburn, nausea, vomiting, and the appearance of aches on the back [4]. Hence, the symptoms of a child sufferer, such as the children at first felt whining, restless; the body temperature is usually increased, appetite decreased. In addition, diarrhea is caused by dehydration due to reduced fluid in the body of diarrhea sufferers due to the rapid disruption of electrolyte fluid that causes dehydration. Therefore the child will feel his body very weak as for signs of abnormalities that occur due to diarrhea in children such as in concave eyelids.

To accelerate the healing of diarrheal disease that occurs in children, the role of professional health officers is significant to solve the problem of diarrhea that occurs in children.

The role of healthcare professionals is required as a health care service executor for people who have the authority to implement the purpose of function to treat diarrhea patients. According to [5], [6] stated that the healthcare professionals as health care personnel assist the community in addressing public health. To minimize the pain of diarrhea patients is the role of health professionals as nursing care can be done by observing the condition of basic human needs through the provision of nursing services and can maintain the state of basic human needs through the provision of health care services using the treatment process professionally. This is following the role of healthcare professionals, who must exercise their role in caring for public health and provide care. Based on the explanation of [7], [8] stated that in carrying out its role, healthcare professionals should be able to perform maintenance functions independently so that patients who are given care can healing and able to perform activities and live normal and healthy returns.

\section{METHODS}

Quantitative methods used in this study are aimed at analyzing statistical data through a set probability sampling non-quota approach. The population studied in this study is 122 professional health professionals who work to treat diarrhea patients in Mataram city hospital. The population studied in this study consisted of 40 at inpatient wards, and 59 health officers working in a patient care room with lowincome community category, and 19 healthcare professionals were working on an intensive ward care unit that worked with diarrhea patients in the hospital. The sample used is obtained based on the criteria of health workers working on hospital inpatient wards as much as 83 health professionals and after the data collected, then analyzed by using Sperman test Rank with $\alpha 0.05$.

\section{RESULT AND DISCUSSION}

The high incidence of diarrhea in children is generally caused by dehydration due to fluid deficiency in the body of diarrhea sufferers. In addition, diarrhea is also caused by the occurrence of intestinal infections due to a lack of nutrients in the body so that there is the growth of pathogenic bacteria in the gut that causes the trigger of diarrhea. This study was conducted in Mataram City Hospital based on data known to many children in patients due to the infection of diarrhea. Based on data that there are $95(95 \%)$ In child patients with mild dehydration symptoms, $25(30.1 \%)$ children, and moderate dehydration symptoms.

Data also shows that the incidence of diarrhea in Mataram annually is always increased, resulting from viruses that cause infections in the intestine. Data showed that in 2018 there was a $13.2 \%$ incidence of diarrhea in children hospitalized, generally diarrhea sufferers in children with a mild level of dehydration $(95 \%)$. Therefore, healthcare professionals who work in the hospital expected to be able to provide optimal care to society, especially in child patients [9]. The importance of professional health officer roles, such as nurses, is undoubtedly not separated from the experience that has been done by the healthcare personnel. The longer the health personnel work is increasingly able to provide nursing care required by patients with diarrhea. Data shows that generally, health workers who have worked more than five years are more professional in taking action to treat child patients. Experience gained can undoubtedly help the diarrhea sufferer to heal faster. Meanwhile, health professionals who work experience of less than five years certainly have been able to work well, but must be under the guidance of professional health professionals (see Fig. 1).

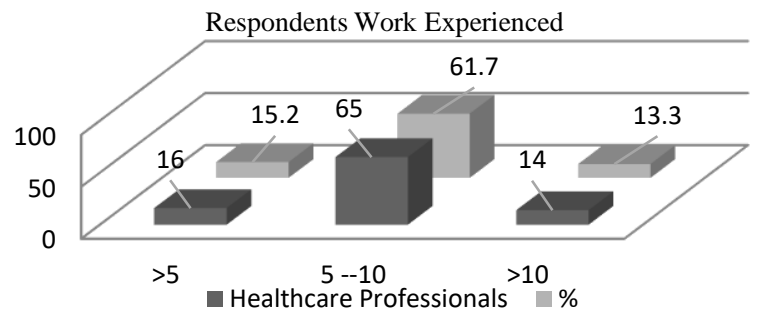

Fig. 1. Distribution of respondents based on the experienced 
The figure above shows that most healthcare professionals have a working experience of more than 5-10 years $(61.7 \%)$. The signified the work experience of most of the healthcare personnel had contributed excellent service to consumers as it can give full attention to the child patient and be satisfied with the performance of the health worker.

In addition to explanations related to work experience, the level of education can also affect the performance performed by healthcare professionals. Therefore, the public would expect a good understanding of health knowledge, especially related to how to overcome the problem of diarrhea. On the other hand, the role of health workers in conducting nurse's actions in the handling of patients with diarrhea problems in children during the period of growth. That the mastery of health sciences is essential for healthcare professionals in conducting preventive action when helping clients of children who suffer from diarrhea pain. [10] said that someone who has a higher level of education would undoubtedly be more comfortable to understand and absorb knowledge, including how to give attention to the focus of his work, to motivate themselves in providing excellent nursing services.

TABEL I. HEALTHCARE PROFESSIONAL DISTRIBUTION BASED ON EDUCATION

\begin{tabular}{|c|c|c|c|}
\hline No & Education & Respondent & $(\boldsymbol{\%})$ \\
\hline 1. & Registered Nurse & 60 & 57 \\
\hline 2. & Bachelor & 23 & 31.6 \\
\hline 3. & Diploma & 12 & 11,4 \\
\hline \multicolumn{2}{|r|}{} & 95 & 100 \\
\hline
\end{tabular}

The Table I above shows that from 95 professional health workforce, 57 percent of the healthcare personnel already know how to handle patients professionally with the education level as a registered nurse who became an implementing health workforce because it already has a good knowledge of excellent service professionally.

The successful supporting factors of health workers in the handling of diarrhea patients in hospitals, in addition to work experience, certainly not regardless of the age factor of health professionals. The importance of age factor in this study because it relates to the ability of health personnel in obtaining information on the proper way in the treatment of diarrhea patients, especially in the child, as an effort to provide excellent service for all patients with diarrhea problems. Maturity affects the mindset and behavior of health workers in making treatment decisions for the patient [11], [12]. The higher the age of health workers, the more appropriate to receive instruction and in carrying out the procedure of service and more responsible. Meanwhile, [13] explained that the growing age of health workers, the level of maturity thinking, and dealing with health measures to the patient would be better too.

In presenting the study result data on the case of diarrhea in children conducted in hospitals, the role of qualified healthcare professionals is necessary for providing nursing care for all healthcare consumers. Based on Fig. 2 regarding the role of healthcare workers, it can be explained that the health workers who work in the hospital have been able to conduct a proper diagnosis of treatment for all patients who experience diarrhea problems by giving the drug fluid through oral treatment of diarrhea due to dehydration through the infusion.

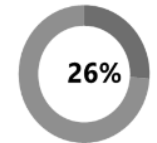

Good (\%)

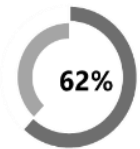

Moderate (\%)

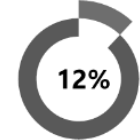

Less $(\%)$
Fig. 2. The role of healthcare professional in treating diarrhea patients

The Fig. 2 shows that health workers' role is necessary for addressing the problem of children with diarrhea. $62 \%$ of health workers are already able to handle the situation of diarrhea that occurs in children. The high level of healing of diarrhea patients in the hospital is not separated from the level of education followed by the health officer. Data shows a close relationship between the level of health education that a healthcare professional has to follow with an important role to do during the handling of patients suffering from diarrhea in the hospital. More details can be seen in Table II below.

TABLE II. THE CORRELATION BETWEEN THE ROLE OF HEALTHCARE PROFESSIONAL AND EDUCATION

\begin{tabular}{|c|c|c|c|c|}
\hline & & & $\boldsymbol{R H}$ & $H E$ \\
\hline \multirow[t]{6}{*}{$\begin{array}{c}\text { Spearman's } \\
\text { rho }\end{array}$} & $\begin{array}{c}\text { Role of } \\
\text { healthcare }(R H)\end{array}$ & $\begin{array}{l}\text { Correlation } \\
\text { Coefficient }\end{array}$ & 1.000 & $-.593^{* *}$ \\
\hline & Sig. (2-tailed) & & . & .000 \\
\hline & $\mathrm{N}$ & & 95 & 95 \\
\hline & $\begin{array}{c}\text { Health } \\
\text { Education }(H E)\end{array}$ & $\begin{array}{l}\text { Correlation } \\
\text { Coefficient }\end{array}$ & $-.593^{* *}$ & 1.000 \\
\hline & Sig. (2-tailed) & & .000 & - \\
\hline & $\mathrm{N}$ & & 95 & 95 \\
\hline
\end{tabular}

Table II shows that 95 healthcare professionals working in the city hospital have performed the right care role in patients with diarrhea. The role of health workers in providing health care to clients following the excellent health processes [14], [15]. Therefore, nurse's role as health professionals should undoubtedly be able to provide excellent health services to give the fulfillment of essential health needs to all clients who are healthy or physically impaired

In identifying the role of health workers working in the city hospital, based on the results of analysis obtained as seen in Table II, that professional labor that works to help clients in the hospital as a result of $66(62 \%)$ Healthcare personnel has been able to carry out their duties as health professionals, especially in addressing the problem of diarrhea. Then the healthcare workers have also provided nursing care to the family in solving the problems of diarrhea that often occur in children [16].

Based on work experience, generally, healthcare professionals have been working for more than five years $(61.7 \%)$. Experienced health workers will undoubtedly be able to provide health services that can give a sense of satisfaction to the patient. According to [17] says that the more experience done by healthcare professionals will also 
influence the suitability of standard services provided to the client as a user of the healthcare service. The length of the working period will undoubtedly affect the quality of service offered to users of health care [18].

They were based on the results (see Table II) that respondents working in the city hospital are generally able to work correctly. This is due to almost all of these health workers have registered nurses [19], so that the responsibility for working in the category of good (62\%). Based on [20] stated that professional health professionals who have higher education will undoubtedly be better able to absorb better knowledge and can focus more on treating patients who are experiencing diarrhea disease. To identify the level of dehydration in children's diarrhea, the study showed that from 95 respondents of diarrhea, 45 (42\%) of others suffer from diarrhea with mild dehydration. In the meantime, $25 \%$ of the clients are severely dehydrated, but all diarrheal diseases experienced by the sufferer can heal well. However, when seen from the symptoms that occur in the client, diarrhea experienced due to the consistency of stool that becomes liquid so that the client feels weak due to the loss of fluid in his body.

\section{CONCLUSION}

The occurrence of diarrhea suffered by sufferers due to the number of fluid out when excessive bowel movements so that the diarrhea sufferers will feel weak due to lack of fluid in the body. To overcome the lack of fluid in the body, then diarrhea sufferers need to be given an infusion accompanied by medication so that the body can be healthy and fit again.

To be able to overcome the problem of diarrheal disease, especially for child sufferers, the role of professional health professionals is necessary as an effort to manage nursing services in the hospital. The role of healthcare personnel as a health care provider for the community is necessary as an effort to sustain human health. The part of healthcare personnel in this study shows that $67 \%$ (56 sufferers) can treat patients with diarrhea well. And based on the case of diarrhea sufferers occurring in Mataram hospital generally experience diarrhea with mild dehydration category $(39.7 \%)$ and $(36.1 \%)$ Diarrhea sufferers with moderate dehydration category. Test result using Spearman Rank Test indicates that the value of $\mathrm{P}$-value of $<\alpha(0.00<0.05)$, meaning that the treatment of diarrhea performed in the hospital of the city by health personnel can be done correctly and adequately.

\section{REFERENCES}

[1] Doré, V., et al. "Comparison of oral, intravenous, and subcutaneous fluid therapy for resuscitation of calves with diarrhea." Journal of dairy science 102.12 (2019): 11337-11348.

[2] Mulatya, Diana Mutuku, and Caroline Ochieng. "Disease burden and risk factors of diarrhoea in children under five years: Evidence from Kenya's demographic health survey 2014." International Journal of Infectious Diseases 93 (2020): 359-366.

[3] Tello, Luis, and Rossana Perez-Freytes. "Fluid and electrolyte therapy during vomiting and diarrhea." The Veterinary Clinics of North America. Small Animal Practice 47.2 (2017): 505.
[4] Getto, Leila, Eli Zeserson, and Michael Breyer. "Vomiting, diarrhea, constipation, and gastroenteritis." Emergency Medicine Clinics 29.2 (2011): 211-237.

[5] Nasirin, Chairun, and Sri Wahyuningsih. "Personal Hygiene and its Effect on the Treatment of After Cesarean Section Debridement in NTB General Hospital." Indian Journal of Forensic Medicine \& Toxicology 14.3 (2020): 1795.

[6] Nouman, Hani, and Ravit Alfandari. "Identifying children suspected for maltreatment: The assessment process taken by healthcare professionals working in community healthcare services." Children and youth services review 113 (2020): 104964.

[7] Carlsson, Eva, et al. "Ways of understanding being a healthcare professional in the role of family member of a patient admitted to hospital. A phenomenographic study." International journal of nursing studies 53 (2016): 50-60.

[8] Latunreng, Wahyuddin, and Chairun Nasirin. "Competitive advantage: Exploring the role of partnership with suppliers, customer relationship and information sharing as antecedents." Journal of Supply Chain Management 8 (2019): 404-411.

[9] Nasirin, Chairun, and Andries Lionardo. "Critical Review Of The Health Administration Promotive Functions In Psychiatric Nursing Practices." Systematic Reviews in Pharmacy 11.12 (2020): 17841786.

[10] Smeltzer, Suzanne CO'Connell, and Brenda G. Bare. Brunner \& Suddarth's textbook of medical-surgical nursing. Philadelphia: JB Lippincott, 1992.

[11] Gagne, Cheryl A., et al. "Peer workers in the behavioral and integrated health workforce: opportunities and future directions." American journal of preventive medicine 54.6 (2018): S258-S266.

[12] Nasirin, Chairun, Andries Lionardo, and Rudy Kurniawan. "Knowledge and Attitudes of Nursing Students in the College of Health in The Face of Global Pandemic Covid-19: Community Empowerment in Preventing Epidemic Disease." (2020).

[13] Geiger, Ben Baumberg, René Böheim, and Thomas Leoni. "The growing American health penalty: International trends in the employment of older workers with poor health." Social science research 82 (2019): 18-32.

[14] Donelan, Karen, et al. "Physician and nurse practitioner roles in emergency, trauma, critical, and intensive care." Nursing Outlook 68.5 (2020): 591-600.

[15] Nasirin, Chairun, and Andries Lionardo. "Effective Implementation of Marketing Management of Hospital Pharmacy: A Study on the Impact of Hospital Service Quality Improvement in Enhancing the of Patients' Satisfaction and Loyalty." Systematic Reviews in Pharmacy 11.5 (2020): 705-712

[16] Smith, Lorna G. "Home treatment of mild, acute diarrhea and secondary dehydration of infants and small children: An educational program for parents in a shelter for the homeless." Journal of Professional Nursing 4.1 (1988): 60-63.

[17] Waldemar, Annette, and Ingela Thylen. "Healthcare professionals' experiences and attitudes towards family-witnessed resuscitation: A cross-sectional study." International emergency nursing 42 (2019): 36-43.

[18] Santana, Idaira Rodriguez, et al. "The impact of extending nurse working hours on staff sickness absence: Evidence from a large mental health hospital in England." International journal of nursing studies 112 (2020): 103611.

[19] Nasirin, Chairun, and Andries Lionardo. "The nurses role in educating the prevention of transmission of the covid-19: A study on improving the healthy living among urban communities." International Journal of Pharmaceutical Research 12.2 (2020).

[20] White, Sam, et al. "Public health education student stereotypes of other health professions before and after an interprofessional education program." Health Professions Education 5.2 (2019): 120125 . 